\title{
Working
}

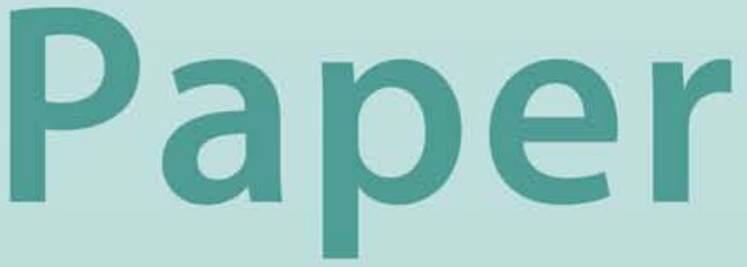




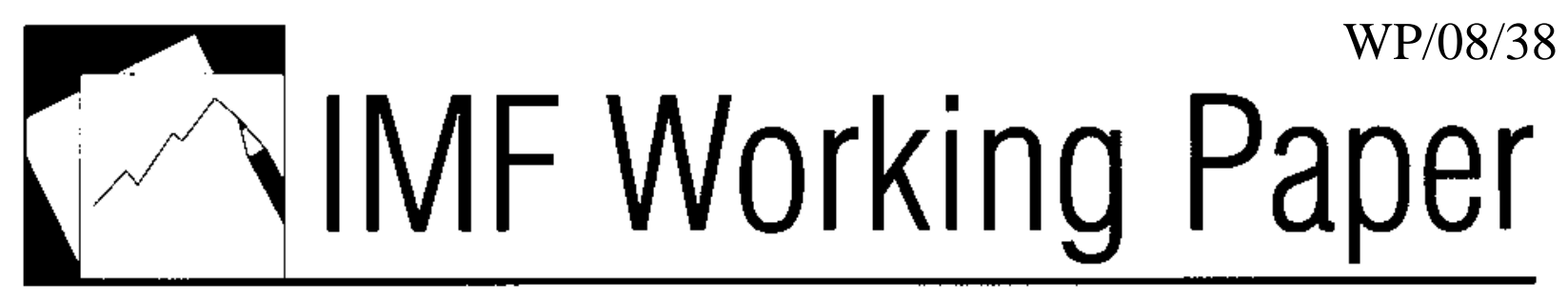

\section{"Beneficial” Delays in Debt Restructuring Negotiations}

Ran Bi 


\title{
IMF Working Paper
}

Research Department

\section{“Beneficial” Delays in Debt Restructuring Negotiations}

\author{
Prepared by Ran $\mathrm{Bi}^{1}$
}

Authorized for distribution by Atish R. Ghosh

February 2008

\begin{abstract}

\section{This Working Paper should not be reported as representing the views of the IMF.}

The views expressed in this Working Paper are those of the author(s) and do not necessarily represent those of the IMF or IMF policy. Working Papers describe research in progress by the author(s) and are published to elicit comments and to further debate.

Delays in debt restructuring negotiations are widely regarded as inefficient. This paper argues that delays can allow the economy to recover from a crisis, make more resources available for debt settlement, and enable the negotiating parties to enjoy a larger "cake". Within this context, therefore, delays may be "beneficial". This paper explores this idea by constructing a dynamic model of sovereign default in which debt renegotiation is modeled as a stochastic bargaining game based on Merlo and Wilson's (1995) framework. Quantitative analysis shows that this model can generate an average delay length comparable to that experienced by Argentina in its most recent debt restructuring.

JEL Classification Numbers:E43, F32, F34
\end{abstract}

Keywords: debt renegotiation, stochastic bargaining, renegotiation delays

Author’s E-Mail Address: $\underline{\text { bi@imf.org }}$

\footnotetext{
${ }^{1}$ I am deeply grateful to Enrique Mendoza, Carlos Vegh, John Shea and Allan Drazen for their insightful advice. I also thank seminar participants at the University of Maryland and the International Monetary fund for their comments. All remaining errors are my own.
} 
I. Introduction $\quad$ Contents $\quad$ Page

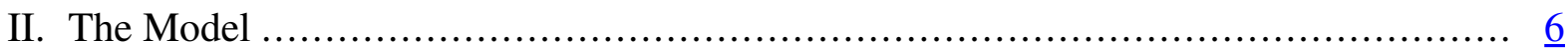

A. Sovereign Government's Problem ..........................................

B. Debt Renegotiation Problem ............................................. $\underline{9}$

C. International Investors' Problem ..............................................

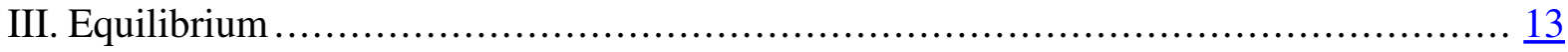

IV. Quantitative Analysis ............................................................ 14

A. Calibration ............................................................ 14

B. Numerical Results on Equilibrium Properties ............................... $\frac{16}{19}$

C. Simulation Results ........................................................ 19

V. Determinants of Renegotiation Delay Length....................................... 21

A. Output Process and Equilibrium Delay Length ............................. 21

B. Other Parameters and Renegotiation Delay Length ........................... 22

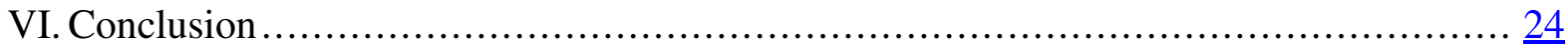

Appendix

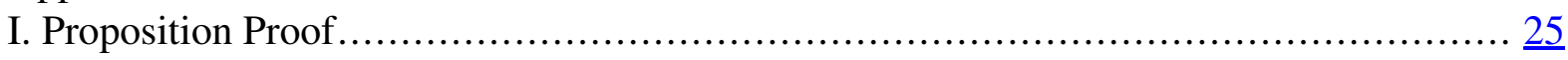

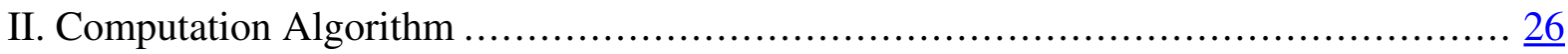

Tables

1. Cases of Sovereign Debt Restructurings ......................................... $\underline{3}$

2. Model Parameter Values .......................................................... $\frac{15}{16}$

3. Target Statistics and Model Statistics ............................................ $\frac{16}{20}$

4. Business Cycle Statistics from the Model and the Data ........................... 20

5. Delay Lengths under Different Output Processes ................................ 21

6. Delay Lengths under Different Parameter Values ..................................... 23

Figures

1. Equilibrium Default Probabilities .................................................. 16

2. Equilibrium Propose/Pass Choices of the Borrower and the Lender..................... $\frac{17}{18}$

3. Equilibrium Debt Recovery Rates.............................................

4. Proposed Debt Repayments................................................... $\frac{18}{19}$

5. Ergodic Distribution of the Equilibrium Delay Length .............................. 19

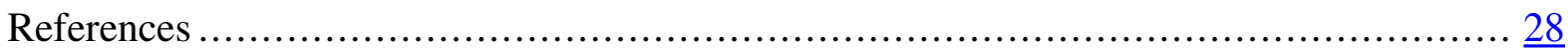




\section{INTRODUCTION}

Many sovereign debt crises are followed by prolonged debt renegotiation processes. Table 1 presents several episodes of sovereign debt restructurings (including those under the Brady Plan and some recent cases), and reports the length of delay experienced in each case as well as the haircut rate agreed upon in the final outcome.

Table 1. Cases of Sovereign Debt Restructurings

\begin{tabular}{lccc}
\hline Countries & $\begin{array}{c}\text { Episode of Restructuring } \\
\text { Negotiation }\end{array}$ & $\begin{array}{c}\text { Delay Length } \\
\text { (Months) }\end{array}$ & $\begin{array}{c}\text { Hair Cut } \\
\text { (Per cent) }\end{array}$ \\
\hline 18 countries $^{1 /}$ & $08 / 1982-05 / 1994$ & 141 & $30-35$ \\
Argentina & $12 / 2001-04 / 2005$ & 40 & 65 \\
Ecuador & $08 / 1999-08 / 2000$ & 12 & 6.5 \\
Pakistan & $02 / 1999-12 / 1999$ & 10 & 30 \\
Russia & $11 / 1998-07 / 2000$ & 20 & 69 \\
\hline
\end{tabular}

1/ Mexico, Argentina, Brazil, Bulgaria, Costa Rica, the Dominican Republic, Ecuador, Ivory Coast, Jordan, Nigeria, Panama, Peru, the Philippines, Poland, Russia, Uruguay, Venezuela and Vietnam.

Sources: Cline (1995), Roubini and Setser (2004) and Sturzenegger and Zettelmeyer (2005).

Such lengthy debt renegotiations are widely regarded as evidence of inefficiencies ${ }^{2}$. This paper argues, however, that delays in a debt renegotiation process may be mutually beneficial for the defaulting country and the debt holders. As documented by Sturzenegger (2002), among others, defaults are usually associated with large output collapses, and few resources are available for repayment following a default. If a debt settlement occurs immediately after the default, then the "cake" to be allocated is quite small. However, if the negotiating parties wait until the economy recovers somewhat to settle the defaulted debt, they may receive higher payoffs by dividing a larger "cake". Within this context, delays may be beneficial.

Our argument is based on two important features of the real world: the output stream is stochastic and no state-contingent debt repayment schedules are available. In the case of a deterministic output process, the defaulting country and the debt holders know exactly what the future "cakes" are, and hence they can reach an agreement right after the default. Similarly, when state-contingent repayment schedules are available, delays are also unnecessary. In the real world, however, the output process after a default is clearly uncertain: although people may expect the economy to recover from the crisis, they do not know exactly what the future output stream will be. Without resort to state-contingent repayment schedules, the negotiating parties may prefer to wait for more information on the economic recovery to be revealed, and then decide if the current state is good enough to settle the defaulted debt.

2 See Roubini and Setser (2004) for a thorough discussion on the inefficiencies in the existing debt restructuring procedures and the proposed institutional reforms . 
The main purpose of this paper is to show, quantitatively, that the "waiting-for-a-larger-cake" consideration can explain the delays experienced by a defaulting country during the renegotiation process, and that these delays can help explain the observed volatility of sovereign bond spreads. To this end, the paper constructs a dynamic model of sovereign default in which renegotiation is modeled using a stochastic bargaining game based on Merlo and Wilson's (1995) framework. The Merlo-Wilson model extends the Rubinstein (1982) alternating offer game by allowing for a stochastic environment and an option to "pass" by the proposer. These two extensions lie at the heart of our argument and make the Merlo-Wilson framework a good one to study the effects of "beneficial" delays. In this paper, the renegotiation process is modeled as a two-player stochastic bargaining game, the simplest case in the Merlo-Wilson framework. The game is played as follows: in each period, a proposer is randomly selected with a constant probability. Based on the current output state and the defaulted debt level, the proposer can either propose or pass. If she chooses to propose, then the other player decides whether to accept or to reject. If the proposal is accepted, then the government repays immediately according to the agreement; otherwise, both players enter the next period and the game repeats. If the proposer chooses to "pass", then again the players enter the next period and the game goes on. This is a game with complete information, but delays may occur in equilibrium whenever the proposer perceives that a better agreement can be achieved by waiting. Intuitively, given the level of the defaulted debt, if the current output state is good enough, an agreement can be reached; otherwise, the proposer chooses to "pass" and thus delays the renegotiation process.

We embed the above debt renegotiation process in a dynamic sovereign debt model featuring endogenous defaults. This part of the model builds on the recent quantitative analysis of sovereign default, such as Aguiar and Gopinath (2006), Arellano (2007) and Yue (2006). In our model, a risk-averse sovereign borrows from a group of risk-neutral, competitive international investors using non-contingent, one-period bonds. Facing a stochastic output stream, the sovereign has the option to default, which results in exclusion from international capital markets and a proportional output loss. The country can re-enter the credit market through renegotiating with the creditors over debt reduction and repayment. The debt recovery rate is endogenously determined in the stochastic bargaining game described above. In equilibrium, sovereign bonds are priced to compensate creditors for the default risk, the expected haircut rate and the cost of delays in the renegotiation.

We first characterize the equilibrium "propose/pass" choices made by each player for all states of output and defaulted debt levels. We find that the identity of the proposer is irrelevant to the timing of an agreement decision; instead, it only affects the allocation of the "cake." For a given defaulted debt level, there is a threshold output level, under which "pass" is always chosen, and above which an optimal debt recovery rate is proposed and accepted. Consequently, given the defaulted debt level, the expected delay length is essentially determined by the output process. 
To investigate the quantitative implications of this model, we calibrate it to the Argentine economy. Numerical analysis shows that the model can generate an average delay length comparable to that experienced by Argentina in its most recent debt restructuring. Furthermore, the model successfully accounts for the observed volatility of bond spreads without assuming risk-averse creditors. In our model, the bond spreads capture not only the default probability and the expected hair cut rate, but also the cost of waiting for an uncertain period of time. The existence of delays adds more uncertainty to the renegotiation outcome, and hence contributes to a larger volatility of bond spreads. In addition, the model simulation accounts for some key features of Argentina's business cycles, such as the countercyclical bond spreads.

Finally, we examine how equilibrium delay length is affected by the properties of the output process. We find that when the output shocks are sufficiently persistent (i.e., the autocorrelation coefficient is larger than 0.3 ), the average delay length increases in the persistence of shocks. More persistent shocks lead to a slower economic recovery following a collapse, resulting in a longer equilibrium delay length. When the output shocks are negatively correlated (with a large absolute value of the autocorrelation coefficient), renegotiation agreements are never achieved after defaults. Although it is least costly for the sovereign to settle the defaulted debt in a good output state, doing so does not bring much benefit in terms of consumption smoothing. With negatively correlated output realizations, a good output state today implies a bad one tomorrow. Even if the sovereign settles the debt today and regains access to the capital markets, it cannot borrow much to smooth consumption tomorrow due to the high default risk associated with a bad output state. Consequently, the sovereign will find it optimal to stay in autarky forever after default. We then explore the effects of output volatility: as volatility increases, the equilibrium delay length tends to be longer, because a more volatile output stream implies a smaller probability that a good enough state will be realized. As a result, the players have to wait longer for a sufficiently large "cake".

Despite widespread concerns about the prolonged and costly sovereign debt restructurings, the existing literature contains few models that can quantitatively explain the observed renegotiation delays. Yue (2006), for example, models the debt renegotiation process using a Nash bargaining game, which excludes delays in equilibrium due to the game's static nature. Arraiz (2006) combines an empirically estimated function of debt settlement probability with a sovereign default model and produces long delays in equilibrium. But those delays mainly result from the empirical estimation of the settlement probabilities. Our paper, on the contrary, obtains sufficiently long delays from an explicit model of the renegotiation process.

In a recent paper, Pitchford and Wright (2007) studies renegotiation delays arising from two inefficiencies: creditor holdout and free-riding on negotiation effort. They model the multi-creditor renegotiation process as a series of bilateral bargaining games. The resulting average delay length is 7 years for a set of countries, close to the average delay length of 5 years generated by the present paper for Argentina. Although Pitchford and Wright (2007) 
models renegotiations explicitly, they do not embed the full-fledged game into the sovereign borrowing framework. Instead, the renegotiation outcomes are taken as parameters when the sovereign makes default decisions. As a result, their model is unable to capture the interactions between defaults and debt renegotiations. Our model improves in this aspect by introducing a dynamic bargaining game into a sovereign default model. Furthermore, delays in Pitchford and Wright (2007) stem from coordination failures, and hence their results may depend on the number of creditors used in the quantitative analysis. Delays in this paper mainly depend on the output process, so the number of creditors is irrelevant.

All the above papers assume explicitly or implicitly that after default, the country has no access to outside financing and the length of exclusion depends on the renegotiation process. Kovrijnykh and Szentes (2007), however, assumes that even if the country is excluded from competitive capital markets, the incumbent creditor, as a monopolist, may continue to invest (though at an inefficiently low level) and the length of exclusion is controlled by the lender. Kovrijnykh and Szentes (2007) shares the same result as this paper: the defaulting country regains access to competitive capital markets only after good shocks. But their paper is based on a different argument: good productivity shocks make the defaulting country's project profitable conditional on efficient investments. The monopolistic lender can then extract more surplus by allowing the defaulting countries to reaccess competitive markets (i.e., reaccess efficient investments) than by retaining the country under her monopolistic power (i.e., with underinvestments). They show that this argument can explain the exclusion from and the returning to competitive capital markets, but the length of exclusion is not quantitatively examined. Our paper, as explained earlier, is based on the "waiting-for-a-larger-cake" argument and we show quantitatively that this argument can generate sufficiently long delays.

The remainder of this paper is organized as follows. We describe the model in Section 2. Section 3 defines the model's equilibrium and characterizes its properties. Model calibration and simulation results are provided in Section 4. In Section 5, we explore how the output process influences the length of renegotiation delays. Effects of other parameters are also reported in this section. Finally we offer concluding remarks in Section 6. The proposition proof and the computation algorithm are in Appendix.

\section{THE MODEL}

This model expands Eaton and Gersovitz's (1981) framework on sovereign default by adding a post-default renegotiation process, which is modeled as a stochastic bargaining game. The game structure is built on Merlo and Wilson (1995).

The model features two types of agents: a small open economy and an infinite number of international investors. The economy faces a stochastic stream of a non-storable consumption good $y_{t}$, drawn from a compact set $Y$. We assume that the exogenous endowment stream follows a log-normal $\mathrm{AR}(1)$ process:

$$
\log \left(y_{t}\right)=\log (\bar{y})+\rho\left(\log \left(y_{t-1}\right)-\log (\bar{y})\right)+\varepsilon_{t}, \quad \varepsilon \sim N\left(0, \sigma_{\varepsilon}^{2}\right)
$$


where $\bar{y}$ is the mean output. In this economy, a risk-averse government maximizes the expected lifetime utility of a representative domestic resident. The preferences of the sovereign government are given by:

$$
E_{0} \sum_{t=0}^{\infty} \beta^{t} u\left(c_{t}\right)
$$

where $0<\beta<1$ is the discount factor, and $c_{t}$ denotes consumption in period $t$. The period utility function $u\left(c_{t}\right)$ is continuous, strictly increasing, strictly concave, and satisfies the Inada conditions.

The government can trade with the international investors via non-contingent one-period zero-coupon bonds. The face value of a discount bond issued in period $t$ is denoted as $b_{t+1}$, specifying the amount to be repaid in period $t+1$. If $b_{t+1}$ is positive, it reflects the government's saving; otherwise, it is a debt. We denote the price of a bond issued in period $t$ as $q_{t+1}$. This price is determined endogenously in equilibrium.

When debt matures, the sovereign can either repay the maturing debt or default. The former option enables the government to trade in the current period and hence to smooth consumption, while the latter results in two penalties: an exogenous proportional output loss ${ }^{3}$ and exclusion from international capital markets during default. Following default, the borrower initiates a renegotiation on debt reduction with its debt holders. This post-default renegotiation is a dynamic bargaining game that determines when an agreement can be reached and how much the sovereign needs to repay in order to reaccess the capital markets. Once an agreement has been reached and the reduced amount of debt has been repaid in full, the sovereign's reputation is restored and it returns to the international capital markets.

International investors, on the contrary, always commit to repaying their debts. They are risk neutral and behave competitively in international capital markets. They can borrow as needed in capital markets at the world risk-free interest rate $r$, which we assume to be constant and unaffected by the size of investors' borrowing and lending. Investors have perfect information on the country's asset holdings and current endowment realizations.

\section{A. Sovereign Government's Problem}

At the beginning of period $t$, an endowment shock $y_{t}$ is realized, and the country inherits an asset position $b_{t}$ and a credit standing $s_{t}$ from the last period. The credit standing can be either good $\left(s_{t}=0\right)$, indicating that the sovereign is current on its debt service, or bad $\left(s_{t}=1\right)$, meaning that the economy is in default.

3 This assumption is empirically relevant. Sturzenegger (2002), for example, estimates the post-default output loss using a panel of 100 countries from 1974 to 1999, and finds that "the experience of the 80s tends to suggest an accumulated $4 \%$ drop in output over the immediately following four years." To keep the model tractable, we assume that this output loss is exogenous . 
If the current period begins with a good credit standing $\left(s_{t}=0\right)$, then the country either repays the maturing debt or defaults on it. Let $V\left(y_{t}, s_{t}, b_{t}\right)$ be the country's lifetime value function from period $t$ on with the current endowment $y_{t}$, credit standing $s_{t}$ and existing asset position $b_{t}$. The value function $V\left(y_{t}, 0, b_{t}\right)$ is then given by

$$
V\left(y_{t}, 0, b_{t}\right)=\max \left\{V^{R}, V^{D}\right\}
$$

where $V^{R}$ is the value function for repaying debt, and $V^{D}$ the one for default. If the sovereign fully repays the maturing debt, then it can borrow or save by trading in one-period bonds. Moreover, the government enters the next period with a good credit standing: $s_{t+1}=0$. Thus, the value of repaying debt is given by

$$
\begin{aligned}
& V^{R}\left(y_{t}, 0, b_{t}\right)=\max _{b_{t+1}} u\left(c_{t}\right)+\beta E V\left(y_{t+1}, 0, b_{t+1}\right) \\
& \text { s.t. } \quad c_{t}=y_{t}-q_{t+1}\left(y_{t}, b_{t+1}\right) b_{t+1}+b_{t}
\end{aligned}
$$

where $b_{t+1}$ is the one-period bond traded in this period, and $q_{t+1}\left(y_{t}, b_{t+1}\right)$ is the corresponding price.

If default is chosen, a proportional output loss $\gamma y_{t}$ and exclusion from the capital markets ensue. The defaulting government then enters the subsequent period with a bad credit standing and a defaulted debt level, $b_{t+1}=(1+r) b_{t}$. To keep the model tractable, we use the risk free interest rate $r$, instead of a bond-specific interest rate, to compute the present value of the defaulted debt. The value function for default, $V^{D}$, is given by

$$
\begin{aligned}
& V^{D}\left(y_{t}, 0, b_{t}\right)=u\left(c_{t}\right)+\beta E V\left(y_{t+1}, 1, b_{t+1}\right) \\
& \text { s.t. } \quad c_{t}=(1-\gamma) y_{t} \\
& b_{t+1}=b_{t}(1+r)
\end{aligned}
$$

If the sovereign starts a period with a bad credit standing $s_{t}=1$, it stays in autarky, suffers a proportional output loss and may settle the defaulted debt through renegotiating with the debt holder on debt reduction. The renegotiation process is a dynamic game that can last more than one period. In equilibrium, this bargaining game determines an endogenous debt recovery rate $\alpha(y, b) \in[0,1]$ and when the agreement on $\alpha(y, b)$ can be reached. Thus, the value of staying in default and continuing renegotiation from period $t$ on, $V\left(y_{t}, 1, b_{t}\right)$, is equal to the expected payoff that the borrower can get from the bargaining game from period $t$ on. We denote this payoff as $\Delta_{B}\left(y_{t}, b_{t}\right)$ :

$$
V\left(y_{t}, 1, b_{t}\right)=\Delta_{B}\left(y_{t}, b_{t}\right)
$$

The determination of this payoff will be discussed in detail in the debt renegotiation problem.

Default is preferable when $V^{D} \geq V^{R}$. Thus, we can characterize the default policy of a sovereign government in good standing by a default set $y^{D}(b) \subseteq Y$, following Arellano (2007). The default set $y^{D}(b)$ is defined as follows

$$
y^{D}(b)=\left\{y \in Y: V^{D}(y, 0, b) \geq V^{R}(y, 0, b)\right\}
$$


This default set specifies a set of endowments for which default is optimal given the debt position $b$. Consequently, we can compute the probability of default, $\theta(b)$, as the probability that the endowment shock falls in the default set, given the government's debt position $b$.

$$
\theta\left(b_{t}\right)=\int_{y^{D}\left(b_{t}\right)} d \mu\left(y_{t+1} \mid y_{t}\right)
$$

\section{B. Debt Renegotiation Problem}

Based on Merlo and Wilson (1995), we model the debt renegotiation problem as a two-player stochastic bargaining game with complete information. This is a stochastic bargaining game in that both the endowment process and the identity of the proposer are stochastic. In each period, a state is realized, which determines the cake (i.e., the set of possible utility vectors to be agreed upon in that period), and the proposer is randomly selected. For simplicity, we assume that each player has a constant probability of being selected as proposer in each period. That is, the identity of the proposer is independent of the cake size. Let $\phi$ denote the probability that the borrower, $B$, can propose in a period, and $(1-\phi)$ is the probability that the lender, $L$, proposes in each period. The frequency with which a player is selected as proposer is a parsimonious way to capture the bargaining power acquired through one's ability to enjoy the first-mover advantage. The proposer may either propose a debt recovery rate or pass. If she proposes, then the remaining party chooses to accept or to reject the proposal. If the proposal is accepted, then the defaulting country immediately repays its reduced debt arrears, and then enters the next period with an upgraded credit standing of $s_{t+1}=0$ without any outstanding debt. If the proposal is rejected, a new output state is realized and the game repeats until an agreement is reached. In the case that the proposer chooses to pass, both players enter the next period and continue the game.

We now define some basic concepts of the game. A stochastic bargaining game may be indexed by $\left(C, \beta, \frac{1}{1+r}\right)$, where for each endowment state $y \in Y, C(y) \subset R^{2}$ is a cake representing the set of feasible utility vectors that may be agreed upon in that state. $\beta$ and $\frac{1}{1+r}$ are the discount factors for $B$ and $L$, respectively ${ }^{4}$. A payoff function is an element $\Delta(y) \in C(y)$, where $\Delta_{i}(y)$ is the utility to player $i, i=B, L$.

As in Merlo and Wilson (1995), we focus on a game with stationary strategies, that is, the players' actions depend only on the current state and the current offer. In equilibrium, the proposer's strategy is to propose when the proposal would be accepted for sure and to pass otherwise. The other player acts passively: she accepts when a proposal is made and waits if the proposer passes. Therefore, we can denote the proposer $i$ 's equilibrium strategy as a

\footnotetext{
4 Merlo and Wilson (1995) assume that the players have the same discount factor. But they also mention that "there is no real restriction implied by the assumption that players discount utility at a common constant rate. So long as the discounted size of the cake converges uniformly to $0 . \cdots$ player dependent discount factors can always be represented by a different cake process with a common fixed discount factor". So in our model we allow the borrower and the lender to have different discount factors .
} 
simple stopping function $\tau_{i}$, with $\tau_{i}=0$ when $i$ proposes and $\tau_{i}=1$ when $i$ passes; the other player accepts or waits accordingly. A stationary subgame perfect (SSP) equilibrium is then defined as the players' equilibrium stationary strategies $\tau_{B}$ and $\tau_{L}$, and the payoff functions, $\Delta_{B}$ and $\Delta_{L}$, associated with these strategies for player $B$ and $L$.

We then proceed to characterize the SSP strategies and payoffs. The expected payoff for the borrower $B$ in period $t, E \Delta_{B}\left(y_{t}, b_{t}\right)$, is given by:

$$
E \Delta_{B}\left(y_{t}, b_{t}\right)=\phi \Delta_{B}^{B}\left(y_{t}, b_{t}\right)+(1-\phi) \Delta_{B}^{L}\left(y_{t}, b_{t}\right)
$$

Here the superscript denotes the identity of the proposer. So $\Delta_{B}^{B}$ represents the borrower's payoff when the borrower himself is the proposer, and $\Delta_{B}^{L}$ refers to the borrower's payoff when the lender is the proposer.

Correspondingly, the expected payoff for the lender $L$ in period $t, E \Delta_{L}\left(y_{t}, b_{t}\right)$, is given by:

$$
E \Delta_{L}\left(y_{t}, b_{t}\right)=\phi \Delta_{L}^{B}\left(y_{t}, b_{t}\right)+(1-\phi) \Delta_{L}^{L}\left(y_{t}, b_{t}\right)
$$

where $\Delta_{L}^{B}$ denotes the lender's payoff when the borrower is the proposer, and $\Delta_{L}^{L}$ refers to the lender's payoff when himself is the proposer.

First consider the case when the borrower $B$ is the proposer. We refer the proposed debt recovery rate as $\alpha^{B}$ and the value of proposing as $V_{B}^{\text {prop }}$. When $B$ proposes and the proposal is accepted, the sovereign repays the agreed amount of debt, $\alpha^{B} b$, immediately and enters the next period with a good credit standing and no outstanding debt. Thus, $V_{B}^{\text {prop }}$ is given by

$$
V_{B}^{\text {prop }}\left(y_{t}, b_{t}\right)=u\left[(1-\gamma) y_{t}+\alpha_{t}^{B} b_{t}\right]+\beta E V\left(y_{t+1}, 0,0\right)
$$

And the lender's payoff from acceptance, $V_{L}^{a c p t}$, is

$$
V_{L}^{a c p t}\left(y_{t}, b_{t}\right)=-\alpha_{t}^{B} b_{t}
$$

When $B$ chooses to pass, the sovereign stays in autarky, suffers the proportional output loss in this period and then enters the next period continuing the bargaining game. We denote the value of passing as $V_{B}^{\text {pass }}$ :

$$
V_{B}^{p a s s}\left(y_{t}, b_{t}\right)=u\left[(1-\gamma) y_{t}\right]+\beta E \Delta_{B}\left(y_{t+1},(1+r) b_{t}\right)
$$

The lender's value of rejecting an offer (or waiting) is denoted as $V_{L}^{r e j t}$, which is given by

$$
V_{L}^{r e j t}\left(y_{t}, b_{t}\right)=\frac{1}{1+r} E \Delta_{L}\left(y_{t+1},(1+r) b_{t}\right)
$$

In equilibrium, the proposer $B^{\prime}$ 's strategy is to propose an $\alpha^{B *}$ that solves the following problem

$$
\alpha^{B *}\left(y_{t}, b_{t}\right)=\operatorname{argmax} V_{B}^{\text {prop }}\left(y_{t}, b_{t}\right)
$$




$$
\begin{array}{ll}
\text { s.t. } & V_{B}^{\text {prop }} \geq V_{B}^{\text {pass }} \\
& V_{L}^{a c p t} \geq V_{L}^{\text {rejt }}
\end{array}
$$

The two constraints specify the set of debt recovery rates acceptable for both players to settle the debt in the current period. If this set is nonempty, then an agreement can be reached in the current period. The stopping function $\tau_{B}\left(y_{t}, b_{t}\right)=0$, meaning that the borrower proposes in this period, and the equilibrium debt recovery rate $\alpha^{B *}$ is the smallest element in this set. In other words, the proposer $B$ can extract extra surplus to the extent that the lender is indifferent between accepting and rejecting. However, if this set is empty, then the borrower would choose to pass $\left(\tau_{B}\left(y_{t}, b_{t}\right)=1\right)$, and hence to delay the renegotiation by one period. This is often the case when the current endowment is low and the future ones are expected to be higher. In these circumstances, the borrower is only willing to repay a small proportion of the debt arrears in the current period, smaller than what the lender expects to get in the future with a better endowment realization (and when the lender himself may get to be the proposer).

Therefore, there is no debt recovery rate that the borrower is willing to offer and the lender is willing to accept. In the end, the borrower just passes and one more period of delay arises.

We now characterize the players' payoff functions. If $\alpha^{B *}$ exists, then the borrower's payoff, $\Delta_{B}^{B}$, is the value of proposing,

$$
\Delta_{B}^{B}\left(y_{t}, b_{t}\right)=V_{B}^{\text {prop }}\left(y_{t}, b_{t}\right)
$$

And the lender's payoff, $\Delta_{L}^{B}$, is the value of accepting,

$$
\Delta_{L}^{B}\left(y_{t}, b_{t}\right)=V_{L}^{a c p t}\left(y_{t}, b_{t}\right)
$$

Otherwise, the borrower's payoff is the value of passing,

$$
\Delta_{B}^{B}\left(y_{t}, b_{t}\right)=V_{B}^{\text {pass }}\left(y_{t}, b_{t}\right)
$$

And the lender's payoff is the value of waiting (equivalent to the value of rejecting):

$$
\Delta_{L}^{B}\left(y_{t}, b_{t}\right)=V_{L}^{r e j t}\left(y_{t}, b_{t}\right)
$$

Similarly, when the lender is the proposer, we denote the proposed debt recovery rate as $\alpha_{t}^{L}$. The value for the lender to propose an acceptable debt recovery rate is $V_{L}^{\text {prop }}$, given by

$$
V_{L}^{\text {prop }}\left(y_{t}, b_{t}\right)=-\alpha_{t}^{L} b_{t}
$$

And the value for the borrower to accept this proposal is $V_{B}^{a c p t}$ :

$$
V_{B}^{a c p t}\left(y_{t}, b_{t}\right)=u\left[(1-\gamma) y_{t}+\alpha_{t}^{L} b_{t}\right]+\beta E V\left(y_{t+1}, 0,0\right)
$$

When $L$ chooses to pass or her proposal is rejected, the value of choosing pass is denoted as $V_{L}^{\text {pass }}$,

$$
V_{L}^{\text {pass }}\left(y_{t}, b_{t}\right)=\frac{1}{1+r} E \Delta_{L}\left(y_{t+1},(1+r) b_{t}\right)
$$


And the borrower's value in this case, $V_{B}^{r e j t}$, is given by

$$
V_{B}^{r e j t}\left(y_{t}, b_{t}\right)=u\left[(1-\gamma) y_{t}\right]+\beta E \Delta_{B}\left(y_{t+1},(1+r) b_{t}\right)
$$

Again, in equilibrium, the proposer $L$ solves the following problem

$$
\begin{aligned}
& \alpha^{L *}\left(y_{t}, b_{t}\right)=\operatorname{argmax} V_{L}^{\text {prop }}\left(y_{t}, b_{t}\right) \\
& \text { s.t. } \quad V_{L}^{\text {prop }} \geq V_{L}^{\text {pass }} \\
& \quad V_{B}^{\text {acpt }} \geq V_{B}^{\text {rejt }}
\end{aligned}
$$

Similar to our argument above, if the minimum debt recovery rate acceptable for $L$ is too large for $B$, then no $\alpha^{L *}$ exists, and $L$ chooses to pass $\left(\tau_{L}\left(y_{t}, b_{t}\right)=1\right)$; otherwise, $L$ proposes and $\tau_{L}\left(y_{t}, b_{t}\right)=0$.

When $L$ proposes, the payoffs for both players, $\Delta_{B}^{L}$ and $\Delta_{L}^{L}$, are given by

$$
\begin{aligned}
& \Delta_{L}^{L}\left(y_{t}, b_{t}\right)=V_{L}^{\text {prop }}\left(y_{t}, b_{t}\right) \\
& \Delta_{B}^{L}\left(y_{t}, b_{t}\right)=V_{B}^{a c p t}\left(y_{t}, b_{t}\right)
\end{aligned}
$$

When $L$ passes, the payoffs are:

$$
\begin{aligned}
& \Delta_{L}^{L}\left(y_{t}, b_{t}\right)=V_{L}^{\text {pass }}\left(y_{t}, b_{t}\right) \\
& \Delta_{B}^{L}\left(y_{t}, b_{t}\right)=V_{B}^{r e j t}\left(y_{t}, b_{t}\right)
\end{aligned}
$$

An SSP equilibrium is a fixed point of the above recursive system(Equations (7) to (26) $)^{5}$.

\section{International Investors' Problem}

The last part of the model specifies the international investors' problem. There is an infinite number of risk neutral and competitive international investors, one of whom is randomly chosen to trade with the sovereign government in each period. Investors choose the face value of the bond to maximize expected profits, taking the bond prices as given

$$
\max _{b_{t+1}} E\left(\pi_{t}\right)
$$

where $\pi_{t}$ is the profit from trading one-period bonds. More explicitly, the expected profit $E\left(\pi_{t}\right)$ can be expressed as

$$
E\left(\pi_{t}\right)= \begin{cases}q_{t+1} b_{t+1}-\frac{b_{t+1}}{1+r} & \text { if } b_{t+1} \geq 0 \\ q_{t+1} b_{t+1}-\frac{1-\theta_{t+1}}{1+r} b_{t+1}+\frac{\theta_{t+1} E\left(\Delta_{L}\left(y_{t+2}, b_{t+2}\right)\right)}{(1+r)^{2}} & \text { if } b_{t+1}<0\end{cases}
$$

\footnotetext{
5 Merlo and Wilson (1995) provides a general proof for this characterization of SSP equilibrium in Theorem 1.
} 
When $b_{t+1} \geq 0$, the government saves by purchasing bonds. Since international investors commit to repaying debts, the government's saving is risk free. When $b_{t+1}<0$, the government borrows by issuing new bonds, and default and debt restructuring are possible future events. In this case, the expected present value of repayment consists of two terms. The first represents the repayment in the following period, while the second reflects the expected debt recovery in the case of default. As noted in the government's problem, the probability of repayment is $\left(1-\theta_{t+1}\right)$, and that of default is $\theta_{t+1}$. In the case of default, debt renegotiation begins in period $t+2 . E\left(\Delta_{L}\left(y_{t+2}, b_{t+2}\right)\right)$ is the expected present value of the payoff that the debt holder can get from the renegotiation game.

From the zero-profit condition of the investors, we obtain the price function as follows:

$$
q_{t+1}= \begin{cases}\frac{1}{1+r} & \text { if } b_{t+1} \geq 0 \\ \frac{1-\theta_{t+1}}{1+r}-\frac{\theta_{t+1} E\left(\Delta_{L}\left(y_{t+2}, b_{t+2}\right)\right)}{(1+r)^{2} b_{t+1}} & \text { if } b_{t+1}<0\end{cases}
$$

Finally, note that the term $-\frac{E\left(\Delta_{L}\right)}{(1+r) b_{t+1}}$ is just the expected present value of the debt recovery rate, which lies in the interval $[0,1]$, and hence the bond price ranges from 0 to the price of a risk free bond. Consequently, the interest rates of sovereign bonds are always higher than or equal to the risk free rate. We define the bond spread as the difference between the country interest rate and the risk free interest rate.

\section{EQUILIBRIUM}

The recursive equilibrium of the model is defined as follows:

Definition 1 A recursive equilibrium is defined by $(i)$ a sequence of allocations of consumption $c(y, s, b)$, bond holding $b^{\prime}(y, b)$ ( $b^{\prime}$ refers to the bond issued in the current period and maturing in the next period), and a default set $y^{D}(b)$; (ii) a pricing function $q\left(y, b^{\prime}\right)$; (iii) the borrower's and the lender's stopping functions $\tau_{B}(y, b)$ and $\tau_{L}(y, b)$, debt recovery rates $\alpha^{B}(y, b)$ and $\alpha^{L}(y, b)$, and the payoffs $\Delta_{B}(y, b)$ and $\Delta_{L}(y, b)$ such that:

1. Given the pricing function $q\left(y, b^{\prime}\right)$ and the debt renegotiation outcome, the country's asset holdings $b^{\prime}(y, b)$, consumption $c(y, s, b)$, and default set $y^{D}(b)$ satisfy the government's optimization problem.

2. Given the bond pricing function $q\left(y, b^{\prime}\right)$, the debt recovery rate $\alpha^{B}(y, b), \alpha^{L}(y, b)$ and the strategies of both players solve the post-default debt renegotiation problem.

3. Given the renegotiation outcome and the country's optimal policy, the bond pricing function $q\left(y, b^{\prime}\right)$ satisfies the investors' maximization problem. 
We can easily establish the relationship between the identity of the proposer and the timing of reaching an agreement.

Proposition 1 In a given period with endowment $y$ and defaulted debt $b$, whether an agreement can be reached in this period does not depend on the identity of the proposer.

\section{Proof. See Appendix.}

This proposition says that in equilibrium, given the endowment realization and the defaulted debt level, no matter who is the proposer, the proposing/pass choice would be the same. The intuition is as follows: if the selected proposer, say the borrower, can find an allocation that makes both parties at least weakly better off by agreeing on the proposal than waiting for one more period, then this allocation is also a feasible choice (but may not be the best one) for the lender to achieve an agreement as the proposer. Therefore, the identity of the proposer does not determine when an agreement is achieved; it only affects the allocation of the "cake" to each player. It is not surprising that being the proposer in an agreement-reaching period is advantageous: the proposer can extract extra surplus to the extent that the other player is indifferent between accepting and rejecting the proposal. Since the identity of the proposer is independent of the state realizations, the player with a higher probability of being proposer in each period is more likely to enjoy the first-mover advantage. Thus, the frequency of being selected as proposer reflects a player's bargaining power.

\section{Quantitative Analysis}

We solve the model numerically to evaluate the delay lengths that can be generated by this model.

\section{A. Calibration}

The model is calibrated to match features of the Argentine economy. We define one period as a quarter.

We use a constant relative risk aversion (CRRA) utility function:

$$
u(c)=\frac{c^{1-\sigma}-1}{1-\sigma}
$$

where $\sigma$ is the risk aversion coefficient. This parameter is set to 2, a standard value in real business cycle studies. We set the parameter of proportional output loss $\gamma$ to be $2 \%$, based on Sturzenegger's (2002) estimate. The quarterly risk-free interest rate $r$ is set to $1 \%$, following Yue (2006).

As mentioned in the model set up, we assume that the exogenous endowment stream follows a log-normal AR(1) process:

$$
\log \left(y_{t}\right)=\log (\bar{y})+\rho\left(\log \left(y_{t-1}\right)-\log (\bar{y})\right)+\varepsilon_{t}, \quad \varepsilon \sim N\left(0, \sigma_{\varepsilon}^{2}\right)
$$


where $\bar{y}$ is the mean output and is normalized to 1 . The autocorrelation coefficient $\rho$ and the standard deviation of endowment innovations, $\sigma_{\varepsilon}$, are computed from the quarterly real GDP data of Argentina from 1980 Q1 to 2005 Q4. The GDP data are seasonally adjusted and are taken from the Ministry of Economy and Production (MECON). The data are detrended using a Hodrick-Prescott filter with a smoothing parameter of 1600 . We then construct a discrete Markov representation of the endowment process as a 51 state Markov chain employing the quadrature procedure by Hussey and Tauchen (1991).

In the last part of the calibration, we set the sovereign's time discount factor $\beta$ and the sovereign's probability of being selected as proposer in each period, $\phi$, simultaneously to match the frequency of default and the average debt recovery rate using the simulated method of moments (SMM).

Table 2. Model Parameter Values

\begin{tabular}{lcl}
\hline Parameter & Value & Sources \\
\hline Coefficient of Risk Aversion & $\sigma=2$ & RBC literature \\
Output Loss in Default & $\gamma=2 \%$ & Sturzenegger (2002) \\
Risk Free Interest Rate & $r=1 \%$ & Yue (2006) \\
\hline Std. Dev. of Endowment Innovations & $\sigma_{\varepsilon}=0.047$ & MECON \\
Autocorr. Coef. of Endowment & $\rho=0.83$ & MECON \\
\hline Discount Factor & $\beta=0.96$ & Matched by Calibration \\
Borrower's Probability of Being Proposer & $\phi=0.60$ & Matched by Calibration \\
\hline
\end{tabular}

Argentina defaulted 4 times from 1824 to 1999 as documented in Reinhart, Carmen M. and Savastano (2003), and then defaulted a fifth time in late 2001. As a consequence, its long-term quarterly default frequency is about $0.70 \%$. In the last 25 years (for which the quarterly GDP data are available), however, Argentina has defaulted twice, once in 1982 and once in late 2001 , resulting in an average quarterly default frequency of $1.92 \%$, much higher than the long-term default frequency. In this calibration, we set the parameter values to match the short-term default frequency. The reason is that in our model, the default decisions and the equilibrium delay lengths are interdependent: states in which defaults are chosen largely determine the renegotiation delay lengths, and the expected delay lengths, in turn, affect the default decisions ex ante. Moreover, both default decisions and equilibrium delay lengths are essentially determined by the output process. Given that the available short series of quarterly GDP data are consistent with a quarterly default frequency of $1.92 \%$, if we artificially set parameter values to match the long-term default frequency (i.e., 0.7\%), then we may get a biased result for the average delay length in the quantitative analysis. Therefore, we aim to match the short-term default frequency of $1.92 \%$. The average debt recovery rate in the most recent Argentine debt restructuring was approximately 35\%(Sturzenegger and Zettelmeyer (2005)). 
The time discount factor is found to be 0.96 , and the sovereign's probability of being proposer, $\phi$, is found to be 0.60 . Our calibrated model generates a default frequency of $2.19 \%$ and an average debt recovery rate of $38.47 \%$, which closely match the corresponding data moments. The calibration results are summarized in Table 2. Table 3 compares the targeted data statistics and the model-generated statistics.

Table 3. Target Statistics and Model Statistics

\begin{tabular}{lcc}
\hline Target Statistics & Data & Model \\
\hline Default Frequency & $1.92 \%$ & $2.19 \%$ \\
Debt Recovery Rate & $35.00 \%$ & $38.47 \%$ \\
\hline
\end{tabular}

\section{B. Numerical Results on Equilibrium Properties}

In this part, we present some of the equilibrium properties of the model. Figure 1 plots the equilibrium default probabilities for each state of output and debt-to-mean output ratio. It is clear that default probabilities are higher with lower endowment realizations and higher levels of debt. In other words, for a given level of debt, the sovereign is more likely to default in bad endowment states. This result supports our argument that defaults are usually associated with bad output realizations, providing incentives to wait for a larger "cake" in the post-default debt renegotiations.

Figure 1. Equilibrium Default Probabilities

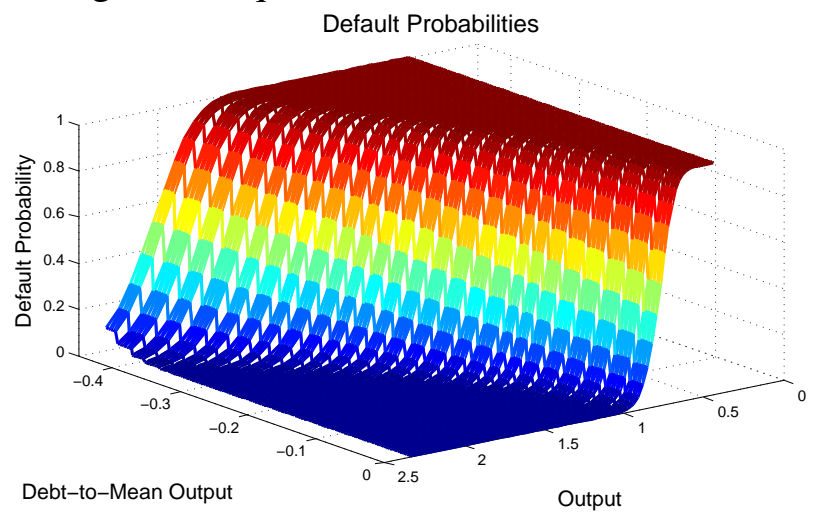


We then present in Figure 2 the equilibrium propose/pass choices made by the borrower and the lender for each endowment state and defaulted debt-to-mean output ratio ${ }^{6}$. On the vertical axes, "Propose" represents the case that a proposal is made and accepted, i.e., an agreement is reached. "Pass", on the contrary, implies waiting and hence one period of delay.

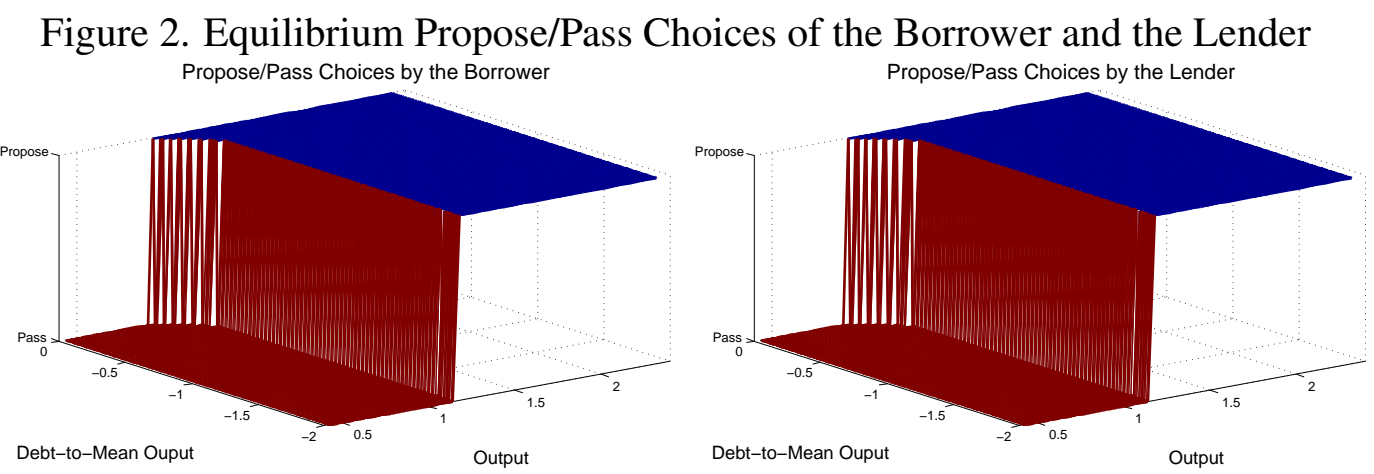

As a confirmation of Proposition 1, the two graphs in Figure 2 are identical, meaning that for a given endowment state and a defaulted debt-to-mean output ratio, the borrower and the lender would make the same propose/pass choice no matter who is selected as proposer.

Furthermore, Figure 2 shows the states in which an agreement can be attained. We observe three interesting results from this figure: first, for any given debt-to-mean output ratio, there is a threshold output level, under which "pass" is chosen; second, for low levels of defaulted debt (e.g., debt-to-mean output ratios smaller than 0.3), the threshold output state increases in debt; third, when the defaulted debt levels are large enough, the output threshold does not change with the debt level. The first two results are very intuitive: debt settlements only occur in sufficiently good output states, and with a higher defaulted debt level, the sovereign needs a better endowment realization (and hence more available resources) to settle the debt. We will discuss the third result later, after we present the renegotiated debt repayment schedules.

We now plot the equilibrium debt recovery rates proposed by each player at each state (Figure 3 ). In this figure, a zero debt recovery rate implies that the proposer chooses to "pass" in the particular state. In general, the debt recovery rates proposed by the borrower are smaller than those proposed by the lender. This is because the proposer enjoys the "first-mover advantage", which results in lower equilibrium debt recovery rates when the borrower is the proposer and higher ones when the lender is the proposer. In addition, the shapes of the two debt recovery schedules are similar: both of them are convex and decreasing in the defaulted debt level, meaning that a lower level of defaulted debt results in a much larger debt recovery rate. These

\footnotetext{
6 In the following figures, "debt" refers to the present value of the defaulted debt. Since it may take many periods to reach a renegotiation agreement, the present value of the defaulted debt can be much larger than the original level at the time of default. Therefore, we allow the largest possible defaulted debt-to-mean output ratio to be $200 \%$, which is large enough (i.e., it is never binding) for our benchmark simulations. Since we use negative numbers to denote debt, the lower bound of the defaulted debt-to-mean output ratio is -2.0 .
} 
debt recovery schedules are also similar to that obtained from a Nash Bargaining game, except that in the latter case there is no delay in equilibrium.

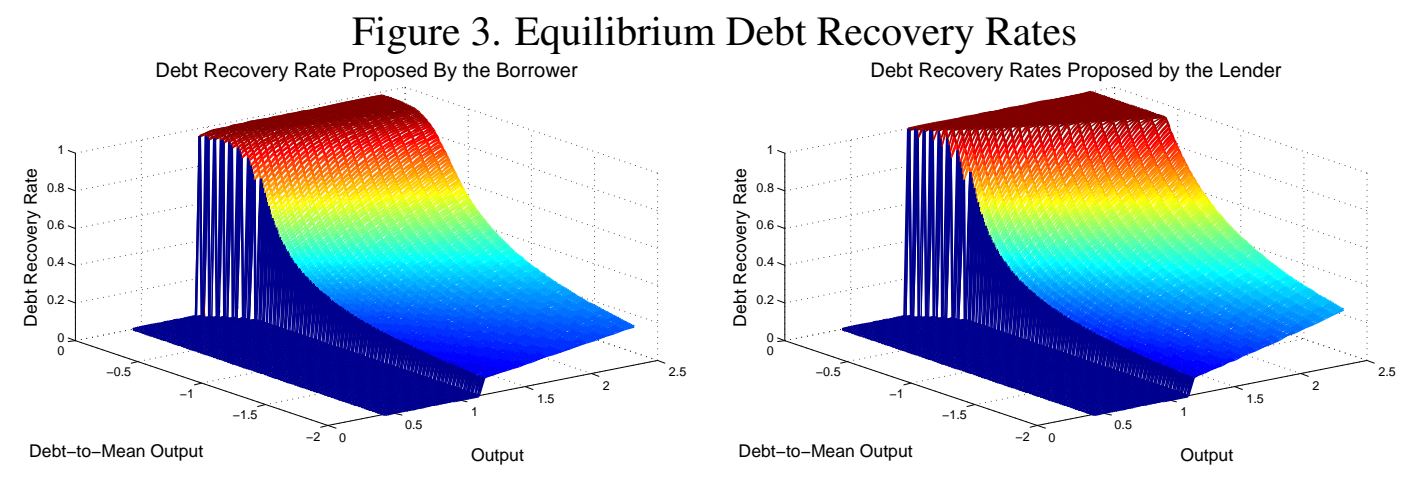

Furthermore, we can take a look at the total debt repayments proposed by each player, as shown in Figure 4.

Figure 4. Proposed Debt Repayments
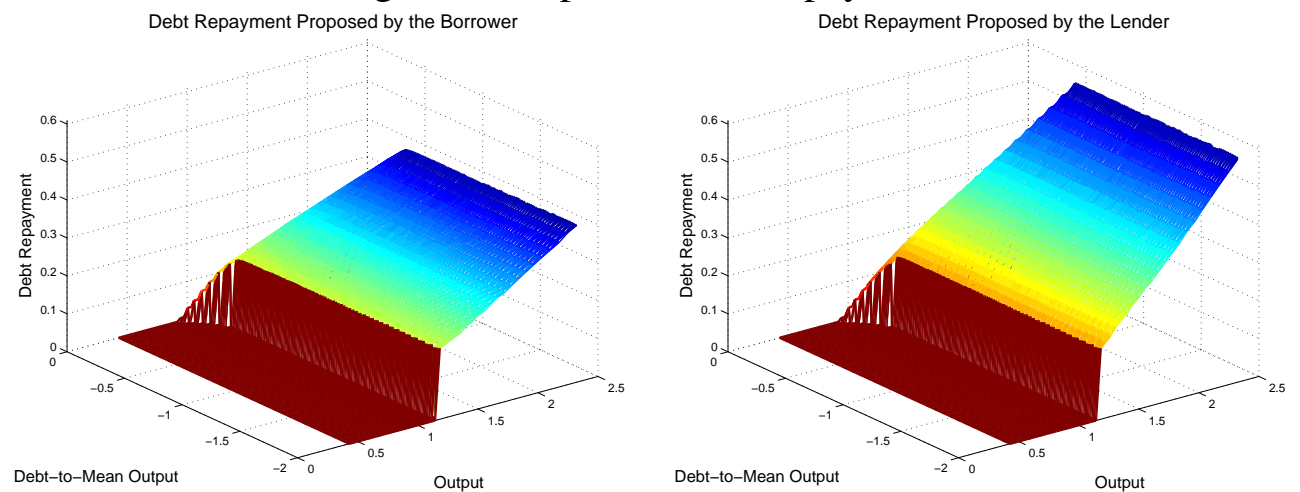

When the proposed debt repayment is zero, it means the proposer passes. Again, the debt repayments proposed by the lender are generally larger than those proposed by the borrower. More interestingly, for a given output state, except for the low defaulted debt region (e.g., the debt-to-mean output ratios smaller than 0.3 ), the proposed repayment does not change with the debt level. In other words, for any given endowment realization, there is a maximum amount that the sovereign is willing to repay, regardless of the defaulted debt level. This explains why the threshold output state is invariant of the defaulted debt level in the large debt region. And again, this result coincides with that from Nash bargaining, which is not surprising given that the bargaining structure in this paper is a variant of the Rubinstein game. Finally, this maximum amount of repayment increases in the output realization. 


\section{Simulation Results}

We conduct 500 rounds of simulations, with 2000 periods per round, and then extract the last 200 periods in each round to study the limiting distribution of the model economy.

First, we show the ergodic distribution of the equilibrium delay length in Figure 5. Equilibrium delay length ranges from zero to about 160 periods (a period is a quarter), while falling between 0 and 20 quarters most frequently.

Figure 5. Ergodic Distribution of the Equilibrium Delay Length

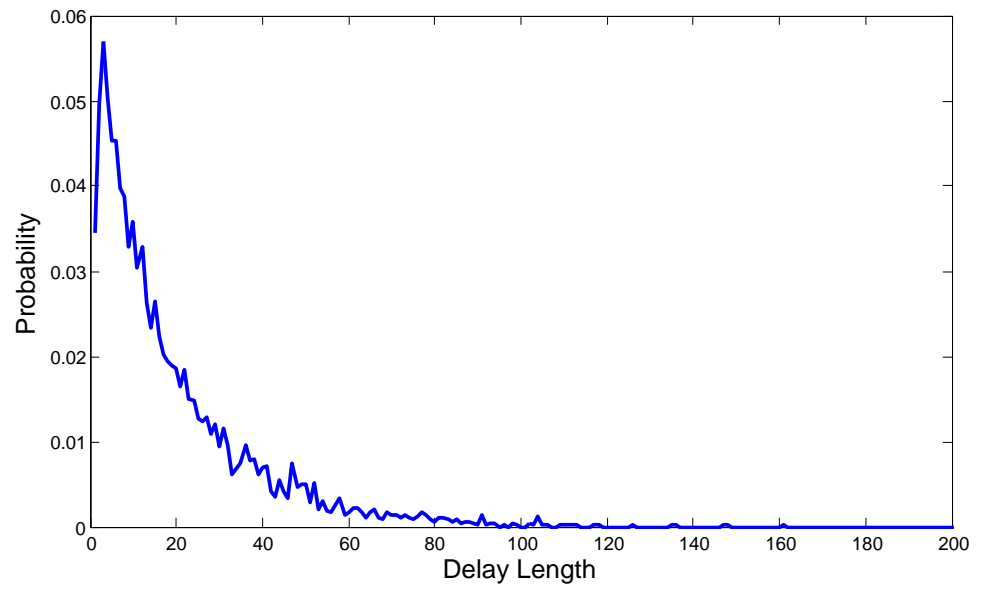

The average delay length, together with other business cycle statistics generated by the model are reported in Table 4. For comparison, we also report the corresponding data statistics in that table. The debt service-to-GDP ratio is computed by dividing Argentina's short-term debt and debt service for long-term debt by its GDP from 1980 to 2005. The debt data are taken from the Global Development Finance database of the World Bank. Seasonally adjusted consumption and current account data from 1980Q1 to 2005Q4 are taken from MECON. Bond spreads are annualized quarterly spreads on 3-year foreign currency denominated bonds issued by the Argentine government, taken from Broner, Fernando and Schmukler (2005).

The model generates an average delay length of about 20 quarters, slightly longer than the actual delay length experienced by the Argentine government. This result suggests that the incentive to wait for a larger "cake" can indeed result in long "beneficial" delays in debt renegotiation processes. The simulated average delay length is a bit too long because of our assumption that the sovereign fully repays the reduced debt arrears right after the agreement. In the real world, the debt arrears are not fully repaid in one step; instead, they are restructured or swapped to new ones, and will be repaid in the future. These debt swap and restructuring provide some state contingency to the debt repayment schedules, which can shorten the renegotiation process. In the extreme case with complete market and state-contingent debt repayment schedules, there would be no delays at all. Therefore, our result can be considered as the "upper bound" of the beneficial delay length. 
Table 4. Business Cycle Statistics from the Model and the Data

\begin{tabular}{lcc}
\hline Statistics & Data & Model \\
\hline Average Renegotiation Delay Length (Quarters) & 13.3 & 19.91 \\
Std. Dev. of Bond Spreads & $1.72 \%$ & $1.37 \%$ \\
Average Bond Spreads & $5.16 \%$ & $3.46 \%$ \\
Correlation between Spreads and Output & -0.54 & -0.51 \\
Debt Service-to-GDP & $14.88 \%$ & $9.28 \%$ \\
Std. Dev. of CA/Output & $5.40 \%$ & $4.00 \%$ \\
Correlation between CA/Output and Output & -0.91 & 0.12 \\
Consumption Std. Dev./Output Std. Dev. & 1.03 & 0.99 \\
\hline
\end{tabular}

The model simulation closely matches the volatility of bond spreads, which has been hard to explain in the literature. The existing quantitative models on sovereign default either assume exogenous return to the capital markets without repaying anything after default (for example, Model I in Aguiar and Gopinath (2006) and Arellano (2007)), or use Nash Bargaining to model the debt renegotiation process (for example, Yue (2006)). In these two cases, the expected length of exclusion from the capital markets is more or less fixed. In the present model, however, the expected length of exclusion is uncertain and depends on the defaulted debt level and the output process. Therefore, the existence of equilibrium delays adds more uncertainty to the debt settlement outcome and contributes to the larger volatility of bond spreads. The model-simulated average bond spread falls below the data statistic, but it is closer to reality than those obtained by other quantitative analysis of sovereign debt. This improvement stems from both the higher default frequency that we target and the additional "waiting cost" incurred during delays, which reflects the forgone earnings from re-investing the defaulted debt.

Furthermore, the model captures the countercyclical behavior of the bond spreads. Bond spreads are higher in bad endowment states due to the higher default risk and the larger potential "waiting cost" following default. The latter arises because the players have to wait longer for the economy to recover from a deeper recession before they can settle the defaulted debt.

The model generates an average debt service-to-GDP ratio of $9.28 \%$, lower than the data statistic $14.88 \%$. Note that we include both short-term debt and debt service of long-term debt in calculating the data statistic, while in the model we only have quarterly (short-term) debt. Therefore, it is not surprising that the the debt-to-GDP ratio generated by the model is a little lower than that observed in data.

The model simulation matches the current account volatility, but it fails to capture the countercyclical behavior of the current account. In this model, the sovereign faces tighter borrowing constraints in recessions than in booms, and therefore has to rely more on its own 
savings, rather than outside financing, to smooth consumption in bad times. Consequently, the sovereign has to save more in booms, resulting in a procyclical current account.

Finally, the simulation generates a consumption stream that is a little less volatile than output. It is typical of emerging economies that consumption is more volatile than output (Neumeyer and Perri (2004)). Aguiar and Gopinath (2006) and Yue (2006) match this fact by assuming a stochastic trend for the output process, implying that output shocks are permanent. The present model has only transitory output shocks and the sovereign aims to smooth consumption over time. Its ability to smooth consumption is quite limited due to the potential default risk, so that the volatility of consumption generated by the simulation is just a little less than that of output.

\section{Determinants of Renegotiation Delay Length}

In this section, we explore the determinants of equilibrium delay length. As aforementioned, the most important parameters are those governing the output process. Hence, we first report the effects of output process on the delay length. We then examine the influence of other parameters, including the discount factor, the probability that the borrower is the proposer, the risk-free interest rate and the proportional output loss following default.

\section{A. Output Process and Equilibrium Delay Length}

In this part, we investigate the effects of output properties on the equilibrium delay length. Table 5 reports the average delay lengths under different values of the autocorrelation coefficient $\rho$ and the standard deviation of endowment innovations, $\sigma_{\varepsilon}$, holding other parameters at their benchmark values.

Table 5. Delay Lengths under Different Output Processes

\begin{tabular}{lc}
\hline Endowment Autocorr. Coef. & $\begin{array}{c}\text { Delay Length } \\
\text { (Quarters) }\end{array}$ \\
\hline$\rho=0.99$ & 44.01 \\
$\rho=\mathbf{0 . 8 3}$ & $\mathbf{1 9 . 9 1}$ \\
$\rho=0.50$ & 10.39 \\
$\rho=0.35$ & 6.12 \\
$\rho \in[-0.3,0.3]$ & $\infty$ \\
$\rho<-0.3$ & $\infty$ \\
\hline Std. Dev. of Endowment Innovations & \\
\hline$\sigma_{\varepsilon}=0.01$ & 12.32 \\
$\sigma_{\varepsilon}=\mathbf{0 . 0 4 7}$ & $\mathbf{1 9 . 9 1}$ \\
$\sigma_{\varepsilon}=0.2$ & 35.72 \\
$\sigma_{\varepsilon}=0.25$ & 59.44 \\
\hline
\end{tabular}


The upper panel shows how the delay length varies with the endowment autocorrelation coefficient. A higher autocorrelation implies more persistent endowment shocks, and hence slower recovery after default. Therefore, the players have to wait longer for a sufficiently large "cake" to materialize. Consistent with this intuition, our results show that as the autocorrelation increases from 0.35 to 0.99 , the renegotiation process lengthens from 6.12 to 44.01 quarters on average.

When the autocorrelation coefficient is too low in absolute value (i.e., when $\rho \in[-0.3,0.3]$ ), the output process is close to i.i.d. with very small volatility ${ }^{7}$. In this case, it is always optimal for the sovereign to stay in autarky forever after default. Intuitively, when the output stream is not volatile, the benefits of smoothing consumption can be smaller than the cost of repaying the reduced debt arrears. As a result, the renegotiation delay length is infinity. When the output realizations are negatively correlated with large absolute values of $\rho$ (i.e., $\rho<-0.3$ ), the output process is again volatile, but the sovereign still chooses to stay in autarky forever once it defaults. The reason is that on the one hand, it is least costly to settle the defaulted debt in good output states, suggesting that the players should reach an agreement in booms; on the other hand, given the negatively autocorrelated output stream, a good state today implies a bad one tomorrow. A bad output state tomorrow tightens the borrowing constraint and limits the sovereign's ability to smooth consumption. Therefore, a costly debt repayment does not provide much benefit for the sovereign in terms of consumption smoothing. In the end, the economy chooses not to settle the debt even in good states.

The lower panel delivers the effects of endowment volatility on delay length. The equilibrium delay length increases as the volatility increases. This result is intuitive: to settle the defaulted debt, we need large positive shocks to materialize. With a more volatile output stream, it is less likely that a good enough shock will occur. Consequently, the players have to wait longer after default for a sufficiently good realization to settle the defaulted debt.

\section{B. Other Parameters and Renegotiation Delay Length}

Table 6 shows the equilibrium delay length under different values for the time discount factor $\beta$, the sovereign's probability of being selected as proposer, $\phi$, the proportional output loss parameter $\gamma$ and the risk-free interest rate $r$.

The upper left panel of Table 6 reports the effects of the time discount factor, holding all other parameters fixed at their benchmark values. Interestingly, the average delay length does not move monotonically as the time discount factor changes. The time discount factor affects the equilibrium delay length through two channels: from the perspective of payoff maximization in the bargaining, a more patient sovereign is willing to wait longer, since its patience enables it to be at a stronger position and thus to enjoy a higher payoff; from the perspective of

\footnotetext{
7 In this exercise, we lower the autocorrelation coefficient $\rho$, while keeping the standard deviation of endowment innovations, $\sigma_{\varepsilon}$, constant. Since $\log (y)$ follows an AR(1) process, its standard deviation $\sigma_{y}=\sigma_{\varepsilon} / \sqrt{\left(1-\rho^{2}\right)}$. As $\rho$ decreases, $\sigma_{y}$ decreases as well .
} 
consumption smoothing, however, a more patient government would like to settle the debt sooner so that it can reaccess the capital markets and smooth consumption in the future. With a large discount factor $(\beta=0.99)$, the second effect dominates the first one, so the equilibrium delay length is shorter than the benchmark case $(\beta=0.96)$. When the discount factor is small (e.g., $\beta=0.85$ ), on the contrary, the first effect dominates, that is, the sovereign cares more about its bargaining payoff, again resulting in a shorter-than-benchmark delay length. In sum, the equilibrium delay length is short when the sovereign is very patient, then it is longer as the sovereign becomes less patient, and finally it is short again when the sovereign is very impatient.

The lower left panel presents the effect of changing the borrower's probability of being selected as proposer. As argued before, this probability captures the borrower's bargaining power. Stronger bargaining power of the government results in a lower debt recovery rate, making it possible for the sovereign to repay the debt arrears even in a not-so-good state after a shorter period of waiting. Also, settling the debt sooner brings two benefits: regaining access to the capital markets sooner and suffering from the output loss for a shorter period of time. Consequently, as the sovereign's probability of being proposer becomes larger, the average delay length is shorter.

The upper right panel delivers the effects of the world interest rate. As the risk-free interest rate increases, the debt-holder in the bargaining becomes more impatient (her discount factor is $\left.\frac{1}{1+r}\right)$. Therefore, she is eager to reach an agreement and get repaid sooner at the cost of a smaller debt repayment. For the sovereign, repaying less and settling the debt sooner are also beneficial. Therefore, the equilibrium delay length is shorter with a higher risk-free interest rate.

Lastly, the lower right panel reports the delay lengths under different values of post-default proportional output loss. Intuitively, when the loss is larger, staying in default is more costly, forcing the sovereign to settle its debt sooner. As a result, the average delay length decreases in the proportional output loss.

Table 6. Delay Lengths under Different Parameter Values

\begin{tabular}{lc|lc}
\hline Discount Factor & $\begin{array}{c}\text { Delay Length } \\
\text { (Quarters) }\end{array}$ & Interest Rate & $\begin{array}{c}\text { Delay Length } \\
\text { (Quarters) }\end{array}$ \\
\hline$\beta=0.99$ & 16.20 & $\mathbf{r}=\mathbf{0 . 0 1}$ & $\mathbf{1 9 . 9 1}$ \\
$\beta=\mathbf{0 . 9 6}$ & $\mathbf{1 9 . 9 1}$ & $r=0.05$ & 8.59 \\
$\beta=0.85$ & 13.77 & $r=0.10$ & 6.51 \\
\hline$B$ 's Prob. of Being Proposer & & Output Loss & \\
\hline$\phi=0.90$ & 10.12 & $\gamma=0.005$ & 23.96 \\
$\phi=\mathbf{0 . 6 0}$ & $\mathbf{1 9 . 9 1}$ & $\gamma=\mathbf{0 . 0 2}$ & $\mathbf{1 9 . 9 1}$ \\
$\phi=0.30$ & 24.29 & $\gamma=0.10$ & 8.68 \\
\hline
\end{tabular}




\section{Conclusion}

Delays in post-default renegotiations are common in sovereign debt restructurings. Contrary to the common wisdom that delays are necessarily costly and inefficient, this paper suggests that delays in reaching a debt restructuring agreement can be an efficient equilibrium outcome. This is because delays allow the economy to recover from a crisis, enabling the negotiating parties to enjoy a larger "cake". To investigate whether this argument can explain the actual delay length experienced by emerging market economies, this paper introduces a stochastic bargaining game with complete information, based on Merlo and Wilson (1995), into an otherwise standard dynamic sovereign default model. We find that for a given defaulted debt-to-output ratio, there exists a threshold output level above which an agreement is reached immediately; otherwise, "pass" is chosen by the proposer and one period of delay occurs. Therefore, in equilibrium, the players tend to wait when the output states are bad, and settle the defaulted debt when the economy recovers and better output states are realized.

Quantitative analysis shows that this model is able to generate a delay length close to that experienced by Argentina in its most recent debt restructuring. Note that this result does not

suggest that an observed delay should necessarily be interpreted as being beneficial. They are beneficial in the context of the present model; other models may generate sufficiently long "inefficient" delays as well.

We then examine how the properties of the output process affect the length of delays. When the volatility of output innovations is held fixed, the equilibrium delay length decreases as the output shocks become less persistent. However, when the persistence is too low (or when the output states are negatively autocorrelated), the sovereign prefers to stay in autarky forever after default, resulting in an infinite delay length. As the volatility of output realizations increases, the equilibrium delay length increases as well, because a more volatile output process makes it less likely that a sufficiently good output will materialize.

This paper is the first one in the sovereign debt literature that quantitatively generates long "beneficial" delays in debt renegotiation processes. It can be made more interesting by assuming a production economy instead of an endowment one, as in this paper. In an economy with investment and production, the recovery path after default becomes endogenous: if the sovereign decides to invest more (and hence sacrifice more of today's consumption), then the economy recovers faster; otherwise, the economy may be trapped in recessions much longer until some exogenous good shock is realized. In the former case, delays are efficient in that the economy is relieved from the debt burden temporarily and the government has more resources for investment, which accelerates the economy's recovery and provides a much larger "cake" for the players to enjoy. In the latter case, however, "waiting" may not be worthwhile because it is almost impossible to predict when a large enough "cake" may materialize and it is quite possible that it will never appear. In such a model set up, multiple equilibria may exist and policies that can induce the government in default onto the "good" track can be welfare-improving. 


\section{Proposition Proof}

Proof of Proposition 1. Suppose $B$ is the proposer in the current period, then the equilibrium debt recovery rate is determined as follows

$$
\begin{gathered}
\alpha^{B *}(y, b)=\operatorname{argmax} V_{B}^{\text {prop }}(y, b) \\
\text { s.t. } \quad V_{B}^{\text {prop }}\left(\alpha^{B *}(y, b)\right) \alpha \geq V_{B}^{\text {pass }}\left(\alpha^{B *}(y, b)\right) \\
V_{L}^{a c p t}\left(\alpha^{B *}(y, b)\right) \geq V_{L}^{r e j t}\left(\alpha^{B *}(y, b)\right)
\end{gathered}
$$

If no such debt recovery rate $\alpha^{B *}$ exists, $B$ chooses to pass.

So in equilibrium, if $B$ chooses to propose, the debt recovery rate $\alpha^{B *}$ ensures $V_{B}^{\text {prop }} \geq V_{B}^{\text {pass }}$ and $V_{L}^{a c p t} \geq V_{L}^{r e j t}$. Then what would $L$ do if she is the proposer in the current period? In this case, there is at least one debt recovery rate that makes "proposing" better than "pass" for the lender himself. This debt recovery rate is just $\alpha^{B *}$, and the value of proposing is equal to $V_{L}^{a c p t}$ above and the value of pass is the same as $V_{L}^{r e j t}$ above. Given that $V_{L}^{a c p t}\left(\alpha^{B *}\right) \geq V_{L}^{r e j t}\left(\alpha^{B *}\right)$, when the lender is the proposer, "proposing" would also be chosen.

If the proposer $B$ chooses to wait, it means there is no $\alpha^{B *}$ satisfying $V_{B}^{\text {prop }} \geq V_{B}^{\text {pass }}$ and $V_{L}^{a c p t} \geq V_{L}^{r e j t}$. In these circumstances, if the identity of proposer is changed to be the lender, then the lender cannot find a feasible debt recovery rate to settle the debt either. Therefore, the lender would also choose "pass".

When the lender is the real proposer, we can show the same thing by the logic above. Thus, Proposition 1 holds. 


\section{Computation Algorithm}

We discretize the spaces of asset holdings, defaulted debts and debt recovery rates using three 201-point grids. The limits of the asset space are set to ensure that they do not bind in equilibrium. The space of defaulted debts is set to be $[-2,0]$, and the lower bound is never hit in simulations. The debt recovery rate has an upper bound of 1 and a lower bound of 0 . The limits of endowment are set to be ten standard deviations above and below the mean output, which is normalized to 1 . We then approximate the distribution of endowment shocks with a 51-point Markov chain using a quadrature based procedure (Hussey and Tauchen (1991)). Then we employ the following algorithm:

I. Guess initial payoffs for the sovereign and the debt holder. Our guess is $\Delta_{B 0}=\Delta_{L 0}=0$.

II. Guess an initial price for bond. Our guess is the risk-free price: $q_{0}=\frac{1}{1+r}$.

III. Guess an initial value for the value function. Our guess is 0 .

IV. Given the initial guesses of $\Delta_{B 0}$, value function, and $q_{0}$, we solve the country's optimization problem when it repays maturing debt. We use Bellman equation iteration to find the value function $V_{0}^{R}$ and the optimal choices for assets. We then compute the value function for default, $V_{0}^{D}$. By comparing $V_{0}^{R}$ and $V_{0}^{D}$, we are able to obtain the government's default decisions for all $y$ and $b$. We also obtain the default set by finding the cut-off endowment shock at which $V_{0}^{R}=V_{0}^{D}$.

V. If the newly-obtained value function is close enough to the old one (we use a numerical tolerance of $10^{-5}$ ), then we proceed to the next step; otherwise, return to step IV using the new value function. Iterate the value function until convergence is obtained and then proceed to step VI.

VI. Given the converged default set and the initial guess of the lender's payoff $\Delta_{L 0}$, we compute the new price $q_{1}$ according to the international investors' problem. If the new price is sufficiently close to the old one, stop iterating on price and continue; otherwise update the price function, repeat step IV and V using the new price function and iterate until price converges.

VII. Given the converged price function and value function, solve the stochastic bargaining game as follows:

(i) When $B$ is the proposer, we first calculate the value of "pass" by $B$, and then the value of rejecting (equivalent to waiting) by $L$. These values do not depend on the proposal made by $B$. We then start a grid search of the debt recovery rate from the lower bound and calculate the value of "proposing" corresponding to each debt recovery rate. Once we find the maximum debt recovery rate that ensures the value of proposing to be larger than, or equal to the value of pass, stop the grid search and record this maximum debt recovery rate. We then 
calculate the values of accepting by the lender for each debt recovery rate from the lower bound to the maximum one we have just recorded, and find the smallest one that makes accepting (at least weakly) better than rejecting. For some $y$ and $b$, such debt recovery rate exists; for the others, no such debt recovery rate exists. Thus, we record the debt recovery rate in the former case and let $\alpha^{B}=0$ in the latter case to denote the choice of pass. Based on the newly found borrower's choices of "proposing" and "pass" and her debt recovery function, we update the borrower and the lender's payoffs.

(ii) When $L$ is the proposer, we follow the same algorithm as in VII(i) except that we first find the minimum debt recovery rate the lender would propose and then do a grid search from this minimum debt recovery rate to the upper bound and find the maximum one in this set that ensures the borrower to accept the proposal. In this step, we can also find the "proposing/pass" choices of the lender and the equilibrium debt recovery function. We then update the payoff functions again. If these payoff functions are sufficiently close to the earlier ones, we stop iterating; otherwise, we return to step IV and redo the whole process using the new payoff functions until convergence is achieved. 


\section{REFERENCES}

Aguiar, Mark and Gita Gopinath, 2006, "Defaultable Debt, Interest Rates and the Current Account," Journal of International Economics, Vol. 69, No. 1, pp. 64-83.

Arellano, Cristina, 2007, "Default Risk and Income Fluctuations in Emerging Economies," American Economic Review. forthcoming.

Arraiz, Irani, 2006, "Default, Settlement, and Repayment History: A Unified Model of Sovereign Debt." Manuscript, University of Maryland.

Atkeson, Andrew, 1991, "International Lending with Moral Hazard and Risk of Repudiation," Econometrica, Vol. 59, No. 4, pp. 1069-1089.

Bolton, Patrick and David Skeel, 2004, "Inside the Black Box: How Sould a Sovereign Bankruptcy Framework Be Structured?," Emory Law Journal, Vol. 53, pp. 763-822.

Broner, Fernando, Guido Lorenzoni and Sergio L. Schmukler, 2005, "Why Do Emerging Markets Borrow Short Term?," World Bank Policy Research Working Paper No. 3389.

Bulow, Jeremy and Kenneth Rogoff, 1989a, "LDC Debts: Is to Forgive to Forget?," American Economic Review, Vol. 79, No. 1. and __ 1989b, "A Constant Recontracting Model of Sovereign Debt," Journal of Political Economy, Vol. 97, No. 1.

Calvo, Guillermo A. and Enrique G. Mendoza, 1996, "Petty Crime and Cruel Punishment: Lessons from the Mexican Debacle," American Economic Review, Vol. 86, No. 2, pp. 170-175.

Chuhan, Puman and Federico Sturzenegger, 2003, "Default Episodes in the 1990s: What Have We Learned?" Manuscript, the World Bank and Universidad Torcuato Di Tella.

Cline, William R., 1995, International Debt Reexamined (Washington: Institute for International Economics).

Eaton, Jonathan and Mark Gersovitz, 1981, "Debt with Potential Repudiation: Theoretical and Empirical Analysis," Review of Economic Studies, Vol. 48, No. 2, pp. 289-309.

Eichengreen, Barry J., Kenneth M. Kletzer and Ashoka Mody, 2003, "Crisis Resolution: Next Steps," NBER Working Paper No. W10095.

Grossman, Herschel I. and Van J. Huyck, 1988, "Sovereign Debt as a Contingent Claim: Excusable Default, Repudiation, and Reputation," American Economic Review, Vol. 78, No. 5, pp. 1088-1097.

Hussey, Robert and George Tauchen, 1991, "Quadrature-Based Methods for Obtaining Approximate Solutions to Nonlinear Asset Pricing Models," Econometrica, Vol. 59, No. 2, pp. 371-396. 
International Monetary Fund, 2003, "Reviewing the Process for Sovereign Debt Restructuring within the Existing Legal Framework," IMF Working Paper.

Kletzer, Kenneth and Brian D. Wright, 2000, "Sovereign Debt as Intertemporal Barter," American Economic Review, Vol. 90, No. 3, pp. 621-639.

Kovrijnykh, Natalia and Balazs Szentes, 2007, "Equilibrium Default Cycles," Journal of Political Economy, Vol. 115, No. 3, pp. 403-446.

Mendoza, Enrique G. and Katherine A. Smith, 2002, "Margin Calls, Trading Costs, and Asset Prices in Emerging Markets: The Finanical Mechanics of the 'Sudden Stop' Phenomenon," NBER Working Papers 9286.

Merlo, Antonio and Charles Wilson, 1995, "A Stochastic Model of Sequential Bargaining with Complete Information,” Econometrica, Vol. 63, No. 2, pp. 371-399. and __ , 1998, "Efficient Delays in a Stochastic Model of Bargaining," Economic Theory, Vol. 11, pp. 39-55.

Neumeyer, Pablo and Fabrizio Perri, 2004, "Business Cycles in Emerging Economies: The Role of Interest Rates," Journal of Monetary Economics, Vol. 52, No. 2, pp. 345-380.

Pitchford, Rohan and Mark L.J. Wright, 2007, "Restructuring the Sovereign Debt Restructuring Mechanism." Research Department Staff Report, Federal Reserve Bank of Minneapolis.

Reinhart, Carmen M., Kenneth S. Rogoff and Miguel A. Savastano, 2003, "Debt Intolerance," NBER Working Paper No. 9908.

Roubini, Nouriel and Brad Setser, 2004, Bailouts or Bail-ins? Responding to Financial Crises in Emerging Economies (Washington: Institute for International Economics).

Rubinstein, Ariel, 1982, "Perfect Equilibrium in a Bargaining Model," Econometrica, Vol. 50, No. 1, pp. 97-110.

Sturzenegger, Federico, 2002, "Default Episodes in the 90s: Fact book and Preliminary Lessons." Manuscript, Universidad Torcuato Di Tella. and Jeromin Zettelmeyer, 2005, "Haircuts: Estimating Investor Losses in Sovereign Debt Restructuring, 1998-2005," IMF Working paper.

Weinschelbaum, Federico and Jose Wynne, 2005, "Renegotiation, Collective Action Clauses and Sovereign Debt Markets," Journal of International Economics, Vol. 67, No. 1.

Yue, Vivian, 2006, “Sovereign Default and Debt Renegotiation.” Manuscript, New York University. 